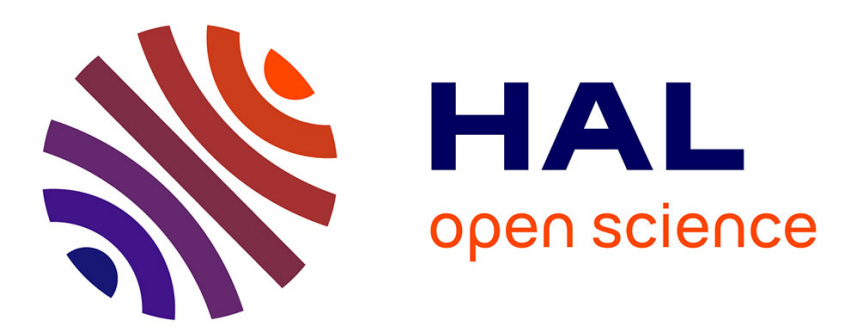

\title{
Temperature dependence of locomotor performance in the tropical clawed frog, Xenopus tropicalis
}

\author{
A. Herrel, Camille Bonneaud
}

\section{To cite this version:}

A. Herrel, Camille Bonneaud. Temperature dependence of locomotor performance in the tropical clawed frog, Xenopus tropicalis. Journal of Experimental Biology, 2012, 215 (14), pp.2465-2470. 10.1242/jeb.069765 . hal-02123569

\section{HAL Id: hal-02123569 \\ https://hal.science/hal-02123569}

Submitted on 8 May 2019

HAL is a multi-disciplinary open access archive for the deposit and dissemination of scientific research documents, whether they are published or not. The documents may come from teaching and research institutions in France or abroad, or from public or private research centers.
L'archive ouverte pluridisciplinaire HAL, est destinée au dépôt et à la diffusion de documents scientifiques de niveau recherche, publiés ou non, émanant des établissements d'enseignement et de recherche français ou étrangers, des laboratoires publics ou privés. 


\title{
Temperature dependence of locomotor performance in the tropical clawed frog, Xenopus tropicalis
}

\author{
Anthony Herrel ${ }^{1, \star}$ and Camille Bonneaud ${ }^{2}$ \\ ${ }^{1}$ UMR 7179 CNRS/MNHN, Département d'Ecologie et de Gestion de la Biodiversité, 57 rue Cuvier, Case postale 55, 75231 Paris \\ Cedex 5, France and ${ }^{2}$ Station d'Ecologie Expérimentale du CNRS à Moulis (USR 2936), 09200 Saint-Girons, France \\ ${ }^{*}$ Author for correspondence (anthony.herrel@mnhn.fr)
}

\begin{abstract}
SUMMARY
Amphibians are ideal taxa with which to investigate the effects of climate change on physiology, dispersal capacity and distributional ranges as their physiological performance and fitness is highly dependent on temperature. Moreover, amphibians are among the most endangered vertebrate taxa. Here we use the tropical clawed frog, Xenopus tropicalis, as a model system to explore effects of temperature on locomotor performance. Our analyses show that locomotion is thermally sensitive, as illustrated by significant effects of temperature on terrestrial exertion capacity (time until exhaustion) and aquatic burst speed (maximal burst swimming velocity and maximal burst swimming acceleration capacity). Exertion performance measures had relatively lower temperature optima and narrower performance breadth ranges than measures of burst speed. The narrow $80 \%$ performance breadths confirm predictions that animals from stable environments should display high thermal sensitivity and, combined with the divergent temperature optima for exertion capacity and burst speed, underscore the vulnerability of tropical species such as $X$. tropicalis to even relatively small temperature changes. The temperature sensitivity of locomotor performance traits in $X$. tropicalis suggests that tropical ectotherms may be impacted by predicted changes in climate.
\end{abstract}

Key words: temperature, endurance, swimming, jumping, frog, climate change, Silurana, Anura.

Received 6 January 2012; Accepted 28 March 2012

\section{INTRODUCTION}

Amphibians are pertinent model taxa with which to investigate the effects of climate change as their physiological performance is highly thermally dependent (Navas et al., 2008; Wilson and Franklin, 2000; Wilson et al., 2000). Moreover, amphibians are among the most endangered vertebrate taxa (Blaustein et al., 2010). Seventy percent of the world's 6300 described amphibian species are experiencing significant species declines and 32\% of amphibians have been classified as threatened or extinct (Wake and Vredenburg, 2008). Vertebrate ectotherms such as amphibians and reptiles are likely sensitive to future climactic change as they have evolved temperature optima that closely match environmental temperatures (van Berkum, 1986; Navas et al., 2008; Angilletta et al., 2010a). Moreover, adult amphibians may show a limited capacity for acclimation, especially if confronted with low seasonal fluctuations in temperature (Wilson et al., 2000). Their permeable skin, limited dispersal capacity and dependence on threatened aquatic habitats for reproduction and development additionally contribute to a high sensitivity to global environmental change (Blaustein et al., 2010; Lawler et al., 2010).

As global surface temperatures are predicted to change by $1.8-4.0^{\circ} \mathrm{C}$ in the next century, with the most extreme changes predicted in the world's biologically most diverse regions, it is important to understand how temperature may affect ecologically relevant performance traits (Beaumont et al., 2011). Indeed, performance is often highly temperature dependent and many species have evolved narrow performance breadths (the temperature range for which they can still perform at, for example, 80 or $95 \%$ of their maximal performance) (Navas et al., 2008; Pörtner and Farrel, 2008; Angilletta, 2006; Angilletta et al., 2010a; Angilletta et al., 2010b). Indeed, as a result of the need to produce multiple enzymes that function at different temperatures for each reaction, the biochemical constraints of a wide performance breadth make thermal generalization costly (Pörtner and Farrell, 2008; Angilletta et al., 2010b). Moreover, thermal optima may be different for different performance traits (e.g. Van Damme et al., 1991), which may limit the ability of a given species to respond to rapid changes in environmental temperature. Indeed, if a species were to adapt to changes in temperature through changes in function of one performance trait, then this could negatively affect other performance traits.

Here we use the tropical clawed frog, Xenopus tropicalis, to explore effects of temperature on locomotor performance. Xenopus tropicalis is distributed throughout the West African rainforest belt (Rödel, 2000) and is fully aquatic, spending the rainy season in pools and puddles of gallery forests and the dry season under rocks and roots of riverbanks. However, during periods of heavy rain, overland dispersal from the forests to nearby savannah ponds has been observed (Rödel, 2000). The mature tropical rainforest habitat of $X$. tropicalis represents a highly stable system with little seasonal temperature fluctuation. Species in such stable environments are predicted to exhibit narrow performance breadths and low acclimation capacity (Navas et al., 2008; Wilson et al., 2000), likely increasing their vulnerability to climate change. At the same time, these habitats, which are among the most diverse on our planet, are predicted to experience extreme climatic stress with average monthly temperatures rising to more than two standard deviations above the 1961-1990 baseline by 2070 (Beaumont et al., 2011; Zelazowski et al., 2011). These changes are likely to affect the distribution and 
abundance of tropical organisms globally, and thus a better understanding of these effects on the potential of animals to cope which such changes is paramount (Beaumont et al., 2011). In this context, understanding the temperature sensitivity of locomotor performance traits in a frog such as $X$. tropicalis may help us understand whether this species might be able to respond to predicted changes in climate. Locomotor performance is likely particularly relevant in this context as it will affect the ability of an organism to escape from predators, catch prey or disperse into novel habitats. Thus, we decided to focus on both aquatic burst performance capacity, which is likely relevant to predator escape and prey capture, and endurance capacity, relevant to the ability of animals to disperse and colonize novel habitats.

\section{MATERIALS AND METHODS Animals}

Xenopus tropicalis (Wagler 1827) were caught in the wild in December 2009 in Cameroon, brought back to France and housed at the Station d'Ecologie Experimentale du CNRS at Moulis. Animals were housed in groups of eight to 10 individuals in aquaria of $60 \times 30 \times 30 \mathrm{~cm}$ and kept at a temperature of $24^{\circ} \mathrm{C}$. This temperature is similar to temperatures measured in the field and close to the optimal and preferred body temperature in Xenopus frogs (Miller, 1982). Animals were fed every other day with beef heart, earthworms or mosquito larvae. All individuals were pittagged (Nonatec, Rodange, Luxembourg) before the onset of the experiments, allowing unambiguous identification of each individual. Animals were kept in the laboratory for 3 months before the onset of the performance trials. Performance capacity at $24^{\circ} \mathrm{C}$ did not decline with time spent in captivity, as frogs measured 9 months later did not differ in their maximal exertion or burst performance capacity. Moreover, burst performance traits measured in the laboratory did not differ from measurements on animals in the field.

\section{Critical temperatures}

Critical thermal maximal and minimal temperatures were measured on 18 adult individuals (10 females, eight males) derived from a single population. Animals were placed individually in plastic containers with water in an incubator of which the temperature was changed gradually $\left(1^{\circ} \mathrm{C} 10 \mathrm{~min}^{-1}\right)$. Animals were checked every $10 \mathrm{~min}$ for a lack of righting response and their body temperatures were measured. Below $15^{\circ} \mathrm{C}$ and above $30^{\circ} \mathrm{C}$ animals were checked every minute. Temperatures were considered to be critical if animals were no longer able to right themselves after having been placed on their back. After the experiments, animals were returned to their aquaria, fed, and allowed to rest for at least 1 week.

\section{Performance}

Performance traits (burst performance and maximal exertion capacity) were measured for the same 18 individuals at six different temperatures $\left(15,20,24,27,30\right.$ and $\left.32^{\circ} \mathrm{C}\right)$. Before the onset of performance measurements, animals were placed for $1 \mathrm{~h}$ in individual containers with water in an incubator set at the target temperature. All performance measurements were repeated three times for each individual with an inter-trial interval of at least $1 \mathrm{~h}$ during which animals were returned to the incubator and allowed to rest. Immediately after the trials we checked body temperature of the animals to make sure it did not deviate more than $1{ }^{\circ} \mathrm{C}$ from the test temperature. At the end of the performance trials, animals were weighed, their pit tag numbers were recorded and they were returned to their home aquaria and fed ad libitum. Animals were given at least 1 week to rest between measurement of different performance parameters (burst performance capacity versus endurance) and at least 1 day between trials at different temperatures. The order of the trial temperatures was assigned using a random table.

Maximal exertion capacity was measured by chasing each individual down a $3 \mathrm{~m}$ long circular track until exhaustion.

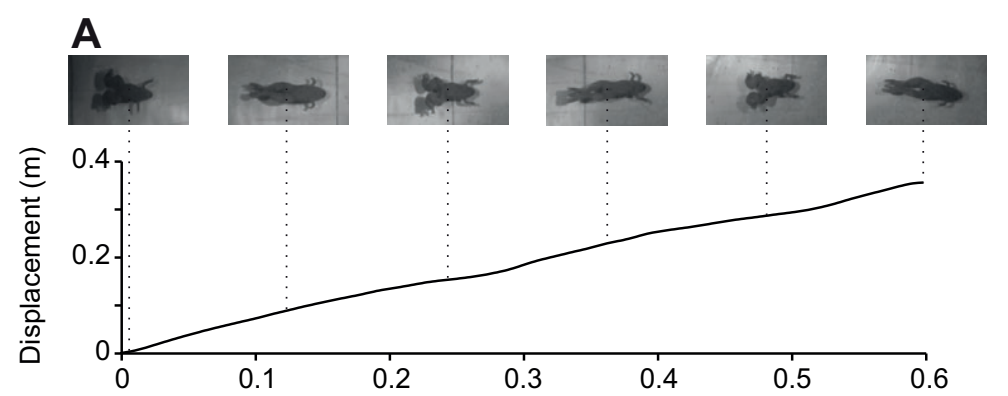

Fig. 1. Analysis of videos used to quantify burst performance. (A) Displacement of the snout in Xenopus tropicalis. A period of two complete swim strokes was tracked on digitized videos. Images were taken from the sequence illustrated.

(B) Instantaneous velocity calculated based on the smoothed displacement profile. (C) Instantaneous acceleration calculated based on the velocity profile. The single highest instantaneous velocity and acceleration values were extracted for each individual for further analysis.
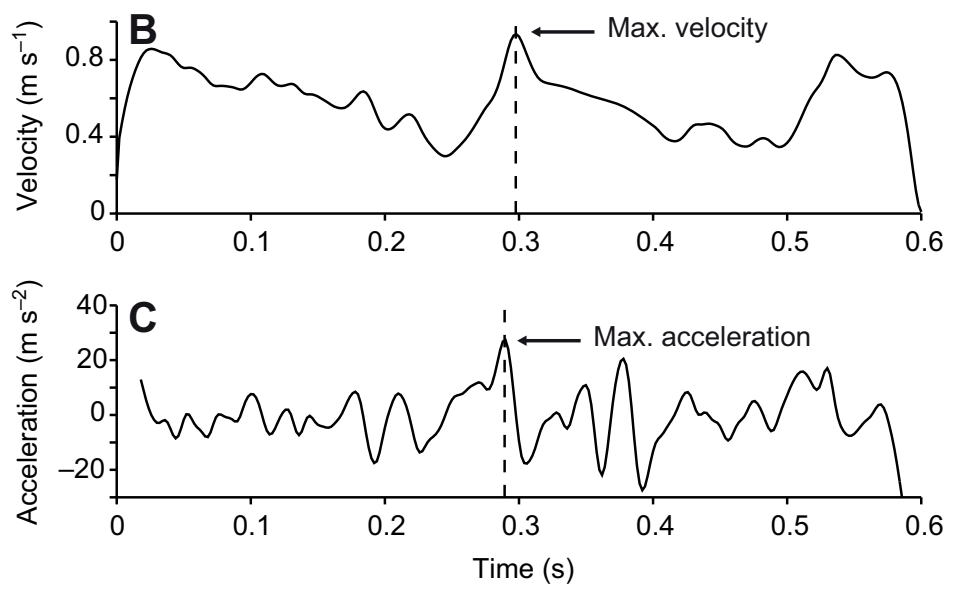
Animals were considered exhausted if they were no longer able to right themselves after having been placed on their back. The floor of the endurance track was covered with cork to improve traction. For each individual, we recorded both the total distance covered and the time spent moving until exhaustion. Note that we were unable to record exertion capacity at $15^{\circ} \mathrm{C}$ because we were unable to cool down the room enough, causing the animals to heat up during the trials. Consequently, results at $15^{\circ} \mathrm{C}$ were discarded from the analysis.

Burst performance capacity was quantified by measuring maximal instantaneous swimming speed and acceleration. Animals were filmed in dorsal view using a Redlake MotionPro high-speed camera (Tallahassee, FL, USA) set at $500 \mathrm{~Hz}$ (Fig. 1). Illumination was provided by two custom-made arrays of eight ultra bright red LEDs. A scale was filmed at the onset of each trial and used to scale measurements in pixels to metric units. Only video clips of good contrast and where the frog swam continuously and in a straight line were retained. Next, video clips were saved, cropped to include at least two locomotor cycles and analyzed using ProAnalyst software (Xcitex, Cambridge, MA, USA). For each frame, the snout tip was digitized either manually or using the auto-tracking routine implemented in ProAnalyst. Raw coordinates were exported to Excel (Microsoft, Redmond, WA, USA) and the displacement of the individual along its path was calculated. Next, the raw displacement profile was smoothed using a zero phase shift low-pass Butterworth filter (Winter, 2004) with the cutoff frequency set at $30 \mathrm{~Hz}$ (Fig. 1). Velocities and accelerations were calculated by numerical differentiation of the smoothed displacement profiles. For each individual, we extracted the single highest instantaneous velocity and acceleration across all swimming sequences recorded (i.e. the fastest velocity and acceleration may thus come from different sequences).

\section{Analyses}

All data were $\log _{10}$-transformed before analyses. A repeatedmeasures ANOVA was used to test the effect of temperature and the interaction between temperature and sex on each of the four performance traits. Next, thermal performance curves were plotted for each individual using the minimum convex polygon method (van Berkum, 1986). Relative performance (the percent of maximal performance achieved at a given temperature) was plotted against temperature and adjacent points were connected using a minimum convex polygon. This approach assumes that the relationship between performance and temperature is gradual and continuous. Note, however, that other methods including Gaussian curve fitting may provide improved estimates of thermal performance curves (Angilletta, 2006). Here we decided to use the minimum convex polygon method as most previously published data have used this method and we wanted to compare results from our study with these data. The use of relative performance measures normalizes differences in absolute performance differences across individuals. From the performance curves, temperature optima and performance breadths for $80 \%\left(T_{\mathrm{pb} 80}\right)$ and $95 \%\left(T_{\mathrm{pb} 95}\right)$ of maximal performance capacity were calculated for each individual. A multivariate ANOVA (MANOVA) was used to test whether temperature optima and performance breadths differed for each performance trait. Subsequent ANOVAs were used to explore how each measure of thermal sensitivity differed for the four performance traits. Bonferroni post hoc multiple comparisons tests were used to examine how temperature dependence differed among performance traits. All analyses were performed using SPSS v. 15.0 (IBM, Armonk, NY, USA).

\section{RESULTS}

The critical thermal minimum (i.e. the temperature at which animals were no longer able to right themselves after being placed on their back) was $12^{\circ} \mathrm{C}$; the critical thermal maximum was $34^{\circ} \mathrm{C}$. A repeated-measures MANOVA indicated that temperature had a significant effect on three of the four performance traits measured (Figs 2, 3, Table 1). Temperature significantly affected the time jumped until exhaustion (Wilks' lambda=0.14, $F_{4,11}=16.40$, $P<0.001$ ). Moreover, although no interaction was found between temperature and sex (Wilks' lambda $=0.68, F_{4,11}=1.30, P=0.33$ ), a significant sex difference in the time jumped until exhaustion was observed, with males displaying a greater time until exhaustion than females $\left(F_{1,14}=5.27, P=0.04\right)$. Temperature did not, however, have a significant effect on the distance jumped until exhaustion (Wilks' lambda $\left.=0.48, F_{4,11}=3.00, P=0.07\right)$, nor on the interaction between temperature and sex (Wilks' lambda=0.69, $F_{4,11}=1.21, P=0.36$ ). However, the distance jumped until exhaustion differed significantly between sexes, with males again outperforming females $\left(F_{1,14}=10.80, P=0.01\right)$. Although temperature significantly affected maximal velocity (Wilks' lambda $=0.12, F_{5,12}=18.18, P<0.001$ ), no significant interaction between temperature and sex was detected (Wilks' lambda $=0.78, F_{5,12}=0.67, P=0.65$ ). Sexes also did not differ in maximal swimming velocity $\left(F_{1,16}=0.70, P=0.42\right)$. Temperature significantly affected maximal acceleration capacity (Wilks' lambda $=0.21, \quad F_{5,12}=8.84, P=0.001$ ); however, no significant interaction was detected between temperature and sex (Wilks' lambda $\left.=0.87, F_{5,12}=0.36, P=0.87\right)$, nor was there a significant
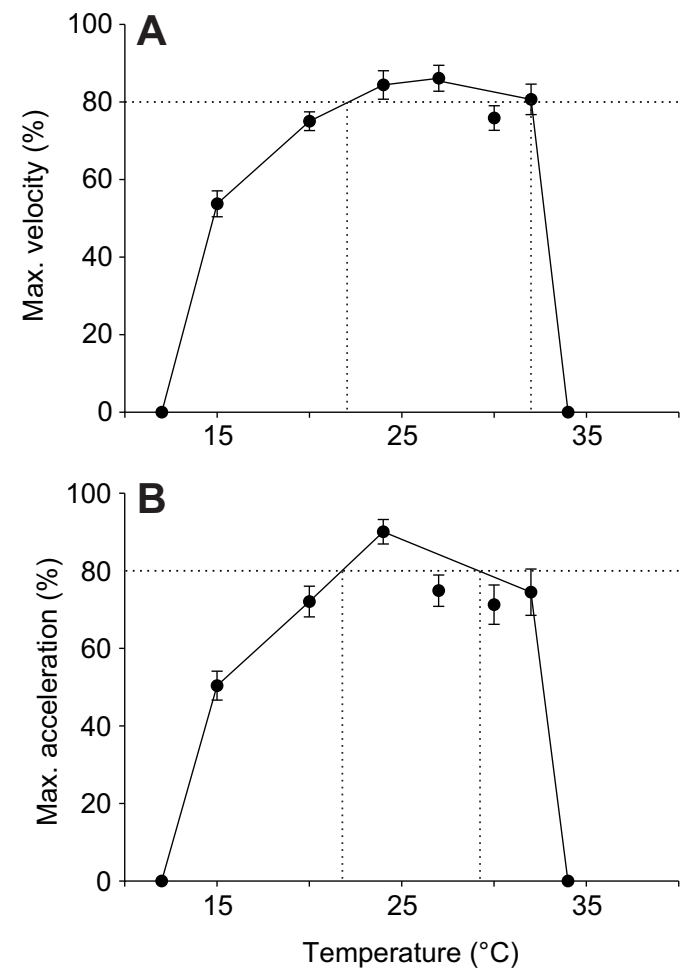

Fig. 2. Mean ( \pm s.e.m.; $N=16$ individuals) percentage of maximum performance for the burst speed measures $(A)$ peak velocity and $(B)$ peak acceleration. The horizontal dotted line represents the $80 \%$ performance breadth, a measure of the temperature range for which frogs can still achieve $80 \%$ of their maximal performance. Note that temperature-performance curves are bound by the critical thermal minimum and maximum temperatures (vertical dotted lines) as determined experimentally. 

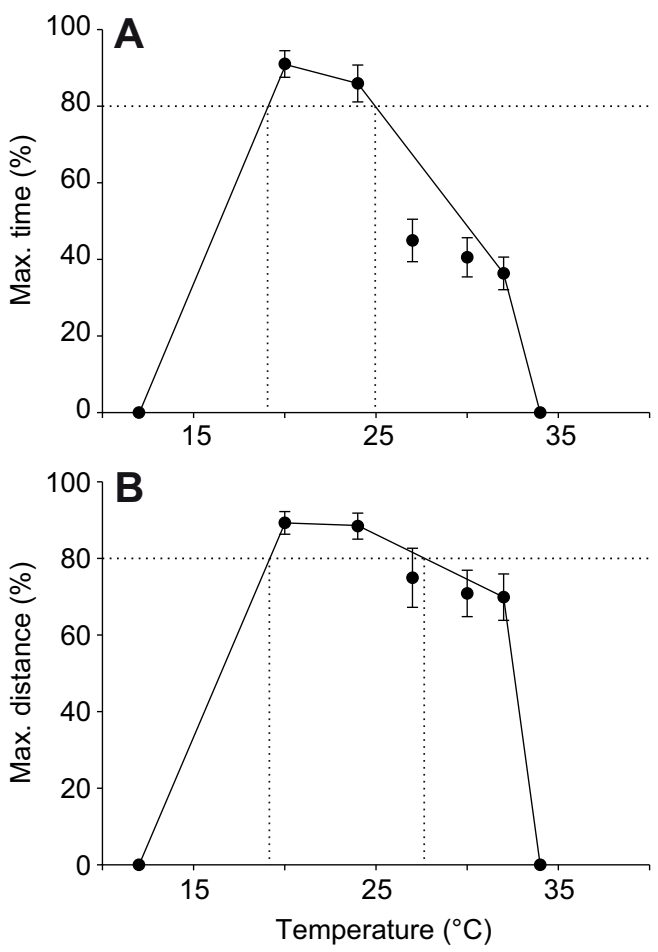

Fig. 3. Mean ( \pm s.e.m.; $N=18$ individuals) percentage of maximum performance achieved for the endurance capacity measures (A) time jumped until exhaustion and (B) distance jumped until exhaustion. The horizontal dotted line represents the $80 \%$ performance breadth, a measure of the temperature range for which frogs can still achieve $80 \%$ of their maximal performance. Note that temperature-performance curves are bound by the critical thermal minimum and maximum temperatures (vertical dotted lines) as determined experimentally.

difference in maximal acceleration capacity between the two sexes $\left(F_{1,16}=1.25, P=0.28\right)$.

Endurance performance measures had relatively lower temperature optima and narrower performance breadths than measures of burst speed (Table 2, Figs 2, 3). A MANOVA showed that the overall temperature effect was significant (Wilks' lambda $\left.=0.39, F_{9,160}=8.50, P<0.001\right)$. Subsequent univariate analyses showed that optimal temperature, $80 \%$ performance breadth and $95 \%$ performance breadth were each significantly different for the four performance traits $\left(T_{\text {opt }}: F_{3,68}=11.76, P<0.001 ; T_{\mathrm{pb} 80}\right.$ : $\left.F_{3,68}=13.90, P<0.001 ; T_{\mathrm{pb} 95}: F_{3,68}=5.00, P=0.003\right)$. Post hoc tests showed that the optimal temperature for the time until exhaustion was significantly different from that for maximal velocity $(P<0.001)$ and maximal acceleration $(P<0.001)$. Moreover, the optimal temperature for the distance jumped until exhaustion was significantly different from that for maximal velocity $(P=0.01)$. The performance breadth at $80 \%$ of maximal capacity was significantly different between the time jumped until exhaustion and all other performance traits $(P<0.001$ for all comparisons). The performance breadth at $95 \%$ of maximal capacity was significantly different between the time jumped until exhaustion and maximal swimming acceleration $(P=0.004)$ and between the time and distance jumped until exhaustion $(P=0.02)$.

\section{DISCUSSION}

Our analyses show that locomotion is thermally sensitive in $X$. tropicalis, as illustrated by significant effects of temperature on one measure of maximal exertion capacity (time jumped until exhaustion) and two measures of burst speed (maximal swimming velocity and maximal swimming acceleration). The absence of a temperature effect on the distance jumped until exhaustion may be an artifact of the limited number of temperatures that were tested (we were unable to obtain data for exertion capacity at $15^{\circ} \mathrm{C}$ ) and the resulting narrow peak in performance measures. Indeed, similar to the other performance traits investigated, this measure showed a trend towards a decrease in performance at high and low temperatures (Fig. 3). No evidence of a significant interaction between temperature and sex was found, indicating that the effect of temperature was sex independent for all locomotor traits. Yet males showed greater maximal exertion capacity than females for the subset of animals included in this study. However, an analysis of a larger number of animals tested at a single temperature $\left(24^{\circ} \mathrm{C}\right)$ showed that, overall, no absolute differences in performance between the sexes exist. Yet, males do show greater relative performance, which may be related to their relatively longer hindlimbs (Herrel et al., 2012). The optimal temperature for performance and performance breadths for 80 and $95 \%$ of maximal capacity were different for each performance trait. Exertion performance measures had relatively lower temperature optima $\left(21.8-24.1^{\circ} \mathrm{C}\right)$ than measures of burst performance capacity $\left(26.6-27.6^{\circ} \mathrm{C}\right.$; Tables 1,2$)$. Note, however, that these results may potentially be biased by the absence of data at $15^{\circ} \mathrm{C}$, thus artificially skewing the optimum to the left. However, even raw data suggest an optimum for measures of exertion capacity that is lower than that for burst performance measures (Table 1).

Interestingly, an analysis of the effects of temperature on burst performance and sustained activity at the muscular level indicated that for both types of measures, hotter was better, with performance increasing with temperature up to $32^{\circ} \mathrm{C}$ (James et al., 2012). The discrepancy between the effects of temperature on muscle contraction (hotter is better) versus the whole-organismal performance (lower optimum for exertion compared with burst performance) illustrates the importance of measuring whole-

Table 1. Raw mean performance data across all individual Xenopus tropicalis at different temperatures

\begin{tabular}{|c|c|c|c|c|}
\hline Temperature & $\begin{array}{l}\text { Max. velocity } \\
\qquad\left(\mathrm{m} \mathrm{s}^{-1}\right)\end{array}$ & $\begin{array}{l}\text { Max. acceleration } \\
\qquad\left(\mathrm{m} \mathrm{s}^{-2}\right)\end{array}$ & $\begin{array}{l}\text { Max. time jumped } \\
\text { until exhaustion (min) }\end{array}$ & $\begin{array}{l}\text { Max. distance jumped } \\
\text { until exhaustion }(\mathrm{m})\end{array}$ \\
\hline $15^{\circ} \mathrm{C}$ & $0.85 \pm 0.05$ & $28.70 \pm 2.15$ & $\mathrm{n} / \mathrm{a}$ & $\mathrm{n} / \mathrm{a}$ \\
\hline $20^{\circ} \mathrm{C}$ & $1.19 \pm 0.04$ & $40.98 \pm 2.18$ & $3.32 \pm 0.76$ & $17.44 \pm 2.87$ \\
\hline $24^{\circ} \mathrm{C}$ & $1.34 \pm 0.07$ & $51.94 \pm 2.54$ & $2.95 \pm 0.75$ & $19.04 \pm 5.13$ \\
\hline $27^{\circ} \mathrm{C}$ & $1.36 \pm 0.06$ & $42.79 \pm 2.44$ & $1.37 \pm 0.09$ & $14.57 \pm 1.20$ \\
\hline $30^{\circ} \mathrm{C}$ & $1.20 \pm 0.05$ & $40.16 \pm 2.61$ & $1.19 \pm 0.11$ & $13.24 \pm 1.08$ \\
\hline $32^{\circ} \mathrm{C}$ & $1.28 \pm 0.07$ & $42.16 \pm 3.26$ & $1.05 \pm 0.06$ & $12.69 \pm 0.75$ \\
\hline
\end{tabular}

Note that we were unable to record exertion capacity at $15^{\circ} \mathrm{C}$.

Data are means \pm s.e.m. ( $N=18$ for exertion capacity, $N=16$ for burst performance capacity). 
Table2. Temperature optima and performance breadths for locomotor performance in $X$. tropicalis

\begin{tabular}{ccccc}
\hline & Max. velocity & Max. acceleration & Max. time & Max. distance \\
\hline$T_{\mathrm{opt}}\left({ }^{\circ} \mathrm{C}\right)$ & $27.56 \pm 3.43$ & $26.56 \pm 3.65$ & $21.78 \pm 2.05$ & $24.11 \pm 3.83$ \\
$T_{\text {pb80 }}\left({ }^{\circ} \mathrm{C}\right)$ & $11.47 \pm 2.39$ & $10.97 \pm 2.67$ & $6.94 \pm 1.94$ & $10.53 \pm 2.85$ \\
$T_{\mathrm{pb} 95}\left({ }^{\circ} \mathrm{C}\right)$ & $4.19 \pm 2.02$ & $5.53 \pm 3.12$ & $2.58 \pm 1.56$ & $5.28 \pm 3.62$ \\
\hline
\end{tabular}

$T_{\mathrm{opt}}$ is the temperature at which performance is optimal. $T_{\mathrm{pb} 80}$ and $T_{\mathrm{pb} 95}$ represent the temperature breadths at which frogs can still achieve 80 and $95 \%$ of their maximal performance, respectively.

Data are means \pm s.d.

organism performance traits when trying to understand the responses of organisms to variation in temperature. Moreover, the difference between the effects observed at these two levels suggests that exertion capacity at the organismal level is limited by the circulatory system rather than by the muscle contractile elements. Finally, optimal temperatures for maximal exertion capacity are close to the operative temperatures measured in the field (approximately $24^{\circ} \mathrm{C}$ ), suggesting that an increase in environmental temperature as a result of global change or local deforestation may significantly affect the overland dispersal capacity of animals such as $X$. tropicalis.

Performance traits related to endurance capacity also had narrower performance breadths than burst performance. Interestingly, thermal performance breadths for $X$. tropicalis are narrower than those reported for hylid tree frogs, which span a wide spectrum of geographic ranges (John-Alder et al., 1988). Moreover, the optimum for swim speed in $X$. tropicalis as measured here was lower than that measured for the subtropical $X$. laevis $\left[27^{\circ} \mathrm{C}\right.$ (Miller, 1982)]. Yet $X$. tropicalis does follow the general trend among amphibians, with tropical species having narrower performance breadths than temperate species (Navas et al., 2008; John-Alder et al., 1988). Ectotherm performance is highly temperature dependent and several studies have found evidence of direct selection on thermal physiology and significant thermal specialization (van Berkum, 1986; Marvin, 2003). For example, jumping performance in the frog Limnodynastes peronii is optimized over its geographic range: populations from cooler climates outperformed those from warmer climatic zones at cooler experimental temperatures, and vice versa (Wilson, 2001).

Characterizing the thermal sensitivity of locomotor performance, and thus understanding how physiological traits may limit distributions and ranges of species, may help identify species at the greatest risk when faced with rapid human-induced climate changes (Pörtner and Farrell, 2008; Chown et al., 2010). Amphibians and reptiles are generally considered to have a conservative thermal ecology, making adaptive shifts in thermal preference potentially difficult (Sinervo et al., 2010). Additionally, aquatic frogs do not have the ability to thermoregulate to the extent that lizards do. Coupled with their lack in physiological plasticity, adult amphibians are likely more sensitive to variation and changes in environmental temperature (Navas et al., 2008). Among ectotherms, those from environments with large daily temperature variation are characterized by a reduced thermal sensitivity. In contrast, ectotherms from highly stable environments (such as tropical regions with little seasonal variation, or aquatic environments in which temperature fluctuations are suppressed by the high thermal conductance of water) are generally more sensitive to changes in temperature (Wilson and Franklin, 2000; Navas et al., 2008), as demonstrated here for $X$. tropicalis.

Our results for $X$. tropicalis confirm predictions that animals from stable environments should show a high thermal sensitivity. The narrow performance breadths, combined with the divergent temperature optima for endurance and burst speed, which may result in a trade-off when adapting to changes in temperature (i.e. adaptation to a temperature that improves burst performance may negatively affect exertion capacity), underscore the vulnerability of $X$. tropicalis. Indeed, temperature changes of even a few degrees could potentially push this species outside its $80 \%$ performance breadth, thus significantly affecting its locomotor capacity and survival. Despite the fact that aquatic frog larvae from fluctuating environments may be able to acclimate to changes in temperature (Wilson and Franklin, 1999), aquatic adult frogs with narrow performance breadths such as Xenopus may also be limited in their ability to acclimate, as has been shown for X. laevis (Miller, 1982). The ability of $X$. tropicalis to thermally acclimate was not tested in the present study, but will provide an important next step in understanding the ability of this species to respond to changes in temperature that are due to global change or local deforestation. Although our results are limited in the number of traits measured, they add to the growing body of literature documenting how temperature affects locomotor performance. Given the importance of locomotion to survival and overall fitness, our data suggest that changes in temperature may have strong affects on the survival of tropical aquatic amphibians. Yet similar data for other species are needed to test the generality of these observations.

\section{ACKNOWLEDGEMENTS}

We would like to thank Legrand Nono Gonwouo and Erik Fokam for their valuable help in the field, N. Bonneaud, P. Provini, O. Calvez and J. Rodriguez for helping to take care of the frogs, M. Antoine for logistical help, and K. Walter for help with the digitizing of swimming sequences and discussions on the paper.

\section{FUNDING}

This research was supported by l'Agence Nationale de la Recherche (ANR) MOBIGEN [ANR-09-PEXT-003 to A.H. and C.B.], a Muséum National d'Histoire Naturelle Action transversale du Muséum (MNHN ATM) grant of the programme 'Biodiversité actuelle et fossile' [to A.H.], and a Marie Curie reintegration grant [FP7-PEOPLE-IRG-2008 no. 239257 to C.B.].

\section{REFERENCES}

Angilletta, M. J., Jr (2006). Estimating and comparing thermal performance curves. J. Therm. Biol. 31, 541-545.

Angilletta, M. J., Jr, Huey, R. B. and Frazier, M. R. (2010a). Thermodynamic effects on organismal performance: is hotter better? Physiol. Biochem. Zool. 83, 197-206.

Angilletta, M. J., Jr, Cooper, B. S., Schuler, M. S. and Boyles, J. G. (2010b). The evolution of thermal physiology in endotherms. Front. Biosci. E2, 861-881.

Beaumont, L. J., Pitman, A., Perkins, S., Zimmermann, N. E., Yoccoz, N. G. and Thuiller, W. (2011). Impacts of climate change on the world's most exceptional ecoregions. Proc. Natl. Acad. Sci. USA 108, 2306-2311.

Blaustein, A. R., Walls, S. C., Bancroft, B. A., Lawler, J. J., Searle, C. L. and Gerasi, S. S. (2010). Direct and indirect effects of climate change on amphibian populations. Diversity 2, 281-313.

Chown, S., Hoffmann, A., Kristensen, T., Angilletta, M., Jr, Stenseth, N. and Pertoldi, C. (2010). Adapting to climate change: a perspective from evolutionary physiology. Clim. Res. 43, 3-15.

Herrel, A., Gonwouo, L. N., Fokam, E. B., Ngundu, W. I. and Bonneaud, C. (2012) Inter-sexual differences in body shape and locomotor performance in the aquatic frog, Xenopus tropicalis. J. Zool. doi: 10.1111/j.1469-7998.2012.00919.x.

James, R. S., Tallis, J., Herrel, A. and Bonneaud, C. (2012). Warmer is better: thermal sensitivity of both maximal and sustained power output in the iliotibialis muscle isolated from adult Xenopus tropicalis. J. Exp. Biol. 215, 552-558. 
John-Alder, H. B., Morin, P. J. and Lawler, S. (1988). Thermal physiology, phenology, and distribution of tree frogs. Am. Nat. 132, 506-520.

Lawler, J. J., Shafer, S. L., Bancroft, B. A. and Blaustein, A. R. (2010). Projected climate impacts for the amphibians of the Western Hemisphere. Conserv. Biol. 24 38-50.

Marvin, G. A. (2003). Effects of acute temperature and thermal acclimation on aquatic and terrestrial locomotor performance of the three-lined salamander, Eurycea guttolineata. J. Therm. Biol. 28, 251-259.

Miller, K. (1982). Effect of temperature on sprint performance in the frog Xenopus laevis and the salamander Necturus maculosus. Copeia 1982, 695-698.

Navas, C. A., Gomes, F. R. and Carvalho, J. E. (2008). Thermal relationships and exercise physiology in anuran amphibians: integration and evolutionary implications. Comp. Biochem. Physiol. 151A, 344-362.

Pörtner, H. O. and Farrell, A. P. (2008). Physiology and climate change. Science 322, 690-692.

Rödel, M. O. (2000). Herpetofauna of West Africa. Vol. 1: Amphibians of the Western Savannah. Frankfurt am Main, Germany: Chimaira.

Sinervo, B., Méndez-de-la-Cruz, F., Miles, D. B., Heulin, B., Bastiaans, E., Villagrán-Santa Cruz, M., Lara-Resendiz, R., Martínez-Méndez, N., CalderónEspinosa, M. L., Meza-Lázaro, R. N. et al. (2010). Erosion of lizard diversity by climate change and altered thermal niches. Science 328, 894-899.

van Berkum, F. (1986). Evolutionary Patterns of the thermal sensitivity of sprint speed in Anolis lizards. Evolution 40, 594-604.
Van Damme, R., Bauwens, D. and Verheyen, R. F. (1991). The thermal dependence of feeding behaviour, food consumption and gut passage time in the lizard Lacerta vivipara Jacquin. Funct. Ecol. 5, 507-517.

Wake, D. B. and Vredenburg, V. T. (2008). Colloquium paper: are we in the midst of the sixth mass extinction? A view from the world of amphibians. Proc. Natl. Acad. Sci. USA 105 Suppl. 1, 11466-11473.

Wilson, R. S. (2001). Geographic variation in thermal sensitivity of jumping performance in the frog Limnodynastes peronii. J. Exp. Biol. 204, 4227-4236.

Wilson, R. S. and Franklin, C. E. (1999). Thermal acclimation of locomotor performance in tadpoles of the frog Limnodynastes peronii. J. Comp. Physiol. B 169, 445-451.

Wilson, R. S. and Franklin, C. E. (2000). Inability of adult Limnodynastes peroni (Amphibia: Anura) to thermally acclimate locomotor performance. Comp. Biochem. Physiol. 127A, 21-28.

Wilson, R. S., James, R. S. and Johnston, I. A. (2000). Thermal acclimation of locomotor performance in tadpoles and adults of the aquatic frog Xenopus laevis. J. Comp. Physiol. B 170, 117-124.

Winter, D. (2004). Biomechanics and Motor Control of Human Movement. New York: John Wiley and Sons.

Zelazowski, P., Malhi, Y., Huntingford, C., Sitch, S. and Fisher, J. B. (2011) Changes in the potential distribution of humid tropical forests on a warmer planet. Philos. Trans. R. Soc. A 369, 137-160. 